\title{
Flow cytometric analysis of within-strain variation in polysaccharide expression by Bacteroides fragilis by use of murine monoclonal antibodies
}

\author{
DEBORAH A. LUTTON, SHEILA PATRICK*, A. D. CROCKARD, LINDA D. STEWARTt, \\ M. J. LARKIN, $†$ EVELYN DERMOTT and T. A. McNEILL
}

Department of Microbiology and Immunobiology, Queen's University of Belfast, Grosvenor Road, Belfast BT12 6BN and + Division of Genetic Engineering, School of Biology and Biochemistry, Queen's University of Belfast, Northern Ireland

\begin{abstract}
Summary. The reactivity of four different monoclonal antibodies (MAbs) with populations of Bacteroides fragilis NCTC 9343, enriched by density gradient centrifugation for a large capsule, small capsule and electron-dense layer (EDL) only visible by electronmicroscopy, was examined. The MAbs reacted strongly with polysaccharides present in both the large capsule- and EDL-enriched populations but not in the small capsule-enriched populations. The pattern of labelling was determined by immunoblotting, immunofluorescence and immuno-electronmicroscopy, and flow cytometry. The MAbs labelled cell membraneassociated epitopes in the large capsule- and EDL-enriched populations and cell-free material in the EDL population. By immunoblotting, ladders of repeating polysaccharide subunits were evident in the EDL population but not in the large capsule population. The proportion of cells labelled within each population was determined by flow cytometry. The reactivity of another MAb with the small capsule population was confirmed by flow cytometry. A qualitative indication of epitope expression was obtained by examination of the flow cytometric profiles. Differential expression of the same saccharide epitope was observed both between and within structurally distinct $B$. fragilis populations. The MAbs were speciesspecific and cross-reacted with several recent clinical isolates. These polysaccharides may be relevant to the virulence of $B$. fragilis.
\end{abstract}

\section{Introduction}

Bacteroides fragilis is a gram-negative anaerobic species that is an important pathogen, commonly encountered in clinical infections. ${ }^{1}$ One of the many factors that undoubtedly contribute to its virulence is the expression of particular surface antigens. ${ }^{2}$ Several authors have described the encapsulating surface structures of $B$. fragilis ${ }^{3-7}$ but, as yet, their relationship to virulence remains unclear. Individual strains of $B$. fragilis have been shown by electronmicroscopy to be heterogeneous with respect to expression of encapsulating surface structures; cells with a large capsule, a small capsule and a marginal electron-dense layer (EDL) may be separated by Percoll density gradient centrifugation. ${ }^{7}$ Within-strain antigenic heterogeneity has been shown immunologically with anti-polysaccharide monoclonal antibodies (MAbs) ${ }^{8,9}$ One MAb reacts with the small capsule but not with the large capsule or EDL. ${ }^{9}$ The surface carbohydrates of $B$. fragilis have been shown by immunochemical analysis to be antigenically complex. Most strains possess four distinct structural elements that can be detected by immunoblotting - a rough type LPS, a common antigen, a smooth LPS which runs as a series of closely spaced bands, and a high $\mathbf{M}_{\mathrm{r}}$ antigen which may be capsular polysaccharide. ${ }^{10}$ How these components relate to the different capsules is not known. The aim of the present study was to obtain MAbs that reacted with the large capsule or EDL populations and to confirm that these structures are antigenically different from the small capsule. Flow cytometry was used to obtain fast and accurate quantitation of bacterial labelling. The reactivity of the MAbs with recent clinical isolates was also determined.

\section{Materials and methods}

\section{Bacterial strains}

The strains used in this study were $B$. fragilis NCTC 9343 (National Collection of Type Cultures, Colindale 
Avenue, London) and BE3 (Department of Medical Microbiology, Vrije Universiteit, Amsterdam), $B$. vulgatus NCTC $10583, B$. thetaiotaomicron NCTC 10582 , B. ovatus ATCC 8483 (American Type Culture Collection), B. distasonis ATCC 8503, and B. gingivalis W83 (Laval University, Quebec, Canada); B. fragilis strains LS1-11, Escherichia coli and Staphylococcus aureus were recent clinical isolates from the Department of Bacteriology, Craigavon Area Hospital, N. Ireland.

\section{Culture methods}

Bacteria were grown in minimal medium defined broth. ${ }^{11}$ Cultures were incubated at $37^{\circ} \mathrm{C}$ in an atmosphere of $\mathrm{H}_{2} 10 \%, \mathrm{~N}_{2} 80 \%, \mathrm{CO}_{2} 10 \%$ in an anaerobic cabinet MK III (Don Whitley Scientific Ltd, Shipley, W. Yorks). Identification was confirmed with the API20A system.

\section{Separation and enrichment of bacterial populations}

Bacterial populations were enriched for different sizes of encapsulating surface structures by Percoll (Pharmacia, Uppsala, Sweden) discontinuous density gradient centrifugation as previously described. ${ }^{7}$

\section{Preparation of bacterial outer membranes}

Outer membranes were prepared as previously described. ${ }^{12}$

\section{Preparation of polysaccharide}

Polysaccharide was extracted by the Proteinase $\mathrm{K}$ method. ${ }^{13}$

\section{Production of MAbs}

A BALB/c mouse was immunised with whole cells of a B. fragilis NCTC 9343 population enriched for expression of the EDL. The mouse was inoculated intraperitoneally with $0.5 \mathrm{ml}$ of a bacterial suspension of $1 \times 10^{8} \mathrm{cfu} / \mathrm{ml}$ in $0.01 \mathrm{M}$ phosphate-buffered saline, pH 7.4 (PBS). A further inoculation of $0.2 \mathrm{ml}$ was given 4 days before the mouse was killed. The spleen cells from the mouse were fused with P3X 63 Ag8-653 (NS-0/1) mouse myeloma cells by treatment with polyethylene glycol 16000 (Sigma) 50\% in RPMI 1640 (Flow Laboratories, Paisley, Scotland) following a modification of the method of Galfre and Milstein. ${ }^{14}$ Hybrid cell lines were selected with hypoxanthineaminopterin-thymidine in RPMI 1640 medium containing myoclone fetal calf serum (Gibco) 20\%. Culture supernates were removed and screened by ELISA and immunofluorescence microscopy for IgG to the EDL population of $\boldsymbol{B}$. fragilis NCTC 9343.

\section{Isotyping}

The isotype of the MAbs was determined with a mouse MAb isotyping kit (Amersham International plc).

\section{Sodium dodecyl sulphate-polyacrylamide gel electrophoresis (SDS-PAGE) and immunoblotting}

SDS-PAGE was performed on vertical slab $8 \%$ gels with the Laemmli buffer system. ${ }^{15}$ For outer membrane proteins, samples were mixed with $50 \mu \mathrm{l}$ of

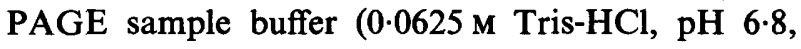
containing SDS $2 \% \mathrm{w} / \mathrm{v}$, glycerol $10 \% \mathrm{v} / \mathrm{v}, 2$-mercaptoethanol $5 \% \mathrm{v} / \mathrm{v}$ and bromophenol blue $0.001 \% \mathrm{w} / \mathrm{v}$ ) and heated in a boiling water bath for $10 \mathrm{~min}$. After cooling, samples were loaded on to gels. For polysaccharide, proteinase $\mathrm{K}$ extracts $(50 \mu \mathrm{l})$ were loaded on to gels. Gels were run at a constant current of $50 \mathrm{~mA} /$ gel. Immunoblotting was performed as previously described. ${ }^{12}$

\section{Culture of bacteria in vivo}

Chambers were constructed, filled with $B$. fragilis NCTC 9343 and implanted in the peritoneal cavity of a mouse as previously described. ${ }^{16}$ The chambers were constructed with $3-\mu \mathrm{m}$ pore membrane filters (Millipore) which allowed the entry of leucocytes.

\section{Electronmicroscopy}

Bacteria were embedded for ultra-thin sectioning as previously described. ${ }^{9}$ For negative staining, one drop of bacterial suspension in distilled water was dried on to a formavar carbon-coated 400-mesh copper grid (Agar Aids) which had been glow-discharged. The grids were labelled with immunogold as previously described. ${ }^{8}$ The thin sections were stained with uranyl acetate for $10 \mathrm{~min}$. The whole bacteria were negatively stained with a drop of methylamine tungstate (Agar Aids) $2 \% \mathrm{w} / \mathrm{v}$ in distilled water. The bacteria were examined with a Phillips CM10 transmission electronmicroscope.

\section{Dual colour immunofluorescence microscopy}

A modification of the staining procedure described by Johnson et al. ${ }^{17}$ was used. Separated bacterial populations were suspended in PBS, fixed on multitest slides (Flow Laboratories) and incubated with MAb supernates. The slides were washed in PBS then incubated with rabbit anti-B. fragilis polyclonal antibody. The slides were again washed and then incubated simulataneously with goat anti-mouse fluorescein conjugate (Sigma) and goat anti-rabbit rhodamine conjugate (Sigma). After a final wash, the slides were examined with a Leitz fluorescence microscope. Random fields of view were selected and the number of bacteria labelled with MAb and polyclonal anti- 
serum were counted. The percentage of each population labelled by MAb was calculated relative to the total number of cells labelled with polyclonal antiserum.

\section{Flow cytometric analyses}

Cells were prepared by a modification of the method of Nelson et al. ${ }^{18}$ PBS that had been filtered three times through $0 \cdot 22-\mu \mathrm{m}$ membrane filters was used throughout. Washed, late exponential phase cultures of $\boldsymbol{B}$. fragilis were resuspended to approximately $2 \times$ $10^{8} \mathrm{cfu} / \mathrm{ml}$ in PBS. Each sample of $1 \mathrm{ml}$ of bacterial suspension was centrifuged at $12000 \mathrm{~g}$ in an Eppendorf 5414 centrifuge for $2 \mathrm{~min}$. The pellets were resuspended in $1 \mathrm{ml}$ of MAb supernate or $1 \mathrm{ml}$ of PBS (control) and incubated at $37^{\circ} \mathrm{C}$ for $1 \mathrm{~h}$. Samples were washed twice in PBS and mixed with $1 \mathrm{ml}$ of appropriately diluted goat anti-mouse IgG fluorescein conjugate (Sigma) or goat anti-mouse IgM fluorescein conjugate (Serotec). The samples were incubated at $37^{\circ} \mathrm{C}$ for $1 \mathrm{~h}$, washed twice in PBS and resuspended in $1 \mathrm{ml}$ of paraformaldehyde $1 \% \mathrm{v} / \mathrm{v}$ in PBS.

Cells stained with FITC conjugate but without primary antibody were negative controls. An IgM $\mathrm{MAb}, \mathrm{Bf} 4$, previously shown to react with the smallcapsule population ${ }^{9}$ was used as a positive control for the fluorescent signal. All samples were sonicated for $20 \mathrm{~s}$ at an amplitude of $5 \mu \mathrm{m}$ (MSE Soniprep 150) to break bacterial aggregates. The sonication time was determined empirically to obtain maximum disruption of bacterial aggregates without cell membrane breakage.

The bacteria were analysed on an EPICS 5 flow cytometer (Coulter Electronics Ltd) equipped with a $5 \mathrm{~W}$ argon laser tuned to $488 \mathrm{~nm}$ and operating at a power output of $100 \mathrm{~mW}$. Before each analysis, the instrument was calibrated with $1 \cdot 5-\mu \mathrm{m}$ fluorescent microspheres (Polysciences). Monodisperse bacterial populations were identified on the basis of size by forward and $90^{\circ}$ light scatter signals and gated appropriately. Single parameter log integral green fluorescence (LIGFL) signals were obtained from the gated population. In each sample, 50000 bacteria were counted and the percentage of positively staining cells was obtained by subtraction of negative control histograms from test histograms with the Immunoprogramme of the instrument.

\section{Results}

\section{Characterisation of $M A b s$ and distribution of epitopes in B. fragilis populations enriched for different encapsulating structures}

$M A b Q U B f 5$. Immunoblotting of proteinase $\mathrm{K}$ extracts with MAb QUBf5, of isotype $\operatorname{IgG}_{2 \mathrm{~b}}$, showed a diffuse staining pattern at the top of the blot, corresponding to a high $M_{r}$ polysaccharide (fig. 1a, b

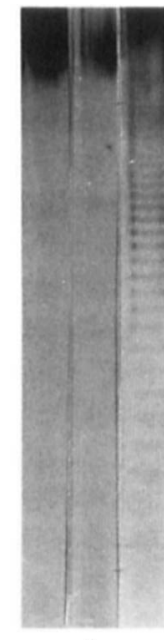

a b c

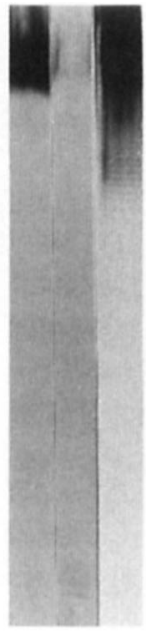

d $\theta$ f

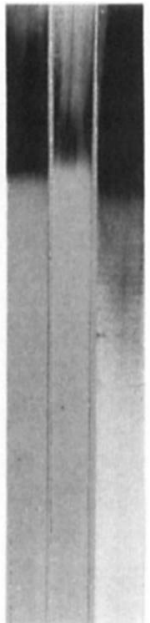

$9 \mathrm{~h}$ i

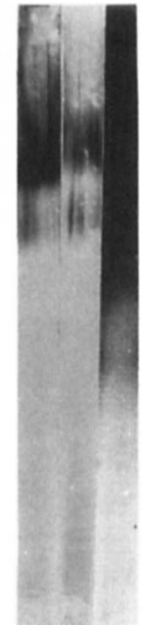

j $k$ I
Fig. 1. Immunoblots from SDS-PAGE gels of proteinase $\mathrm{K}$ extracts of $B$. fragilis NCTC 9343. Lanes $\mathbf{a}, \mathbf{d}, \mathbf{g}$ and $\mathbf{j}$ : large capsule population; lanes $\mathbf{b}, \mathbf{e}, \mathbf{h}$ and $\mathbf{k}$ : small capsule population; lanes $\mathbf{c}, \mathbf{f}$, i and I: EDL population. The blots were probed with MAbs QUBf5 (lanes a-c), QUBf6 (lanes d-f), QUBf7 (lanes g-i) and QUBf8 (lanes j-1).

and c). This polymer was present in smaller amounts in the small capsule population (fig. 1b). A series of discrete bands of repeating polysaccharide subunits was found to extend from the high $\mathbf{M}_{\mathbf{r}}$ polysaccharide to the gel front in the EDL population (fig. 1c). Electronmicroscopy and immunogold labelling with MAb QUBf5 identified a surface-associated antigen located on the membranes of whole bacteria and on membrane vesicles or blebs. Only a proportion of the bacteria within the large capsule and the EDL populations was labelled (not illustrated). Cells from the small capsule population did not react with $\mathrm{MAb}$ QUBf5 but labelled blebs appeared to be secreted from unlabelled cells (fig. 2A). The QUBf5 epitope was readily released from the large capsule population in association with membrane blebs (fig. 2B) and from the EDL population as both membrane blebs and cellfree material (not illustrated).

The budding of vesicles from the outer membrane of $B$. fragilis has been observed (fig. 3A). These vesicles may carry encapsulating material (fig. 3B).

$M A b s Q U B f 6$ and $Q U B f 7$. Two IgG ${ }_{1}$ MAbs, QUBf6 and QUBf7, each reacted with high $\mathbf{M}_{\mathrm{r}}$ polysaccharides to give diffuse staining bands at the top of the immunoblots (fig. 1d-i). The quantity of labelled polysaccharide was less in the small capsule population (fig. le and h). Associated fine ladders of repeating polysaccharide subunits were detected in the EDL population (fig. 1f and i). Heterogeneous labelling of the large capsule (fig. 4A) and the EDL (not illustrated) populations was detected by electronmicroscopy and immunogold labelling with each MAb. Labelled cells were not seen in the small capsule population with either MAb, although some cell-free material was detected by MAb QUBf7 (fig. 4B). Cell-associated polysaccharides were recognised by each MAb in the large capsule (fig. 4C) and the EDL (fig. 4D) populations as illustrated with MAb QUBf7. These 

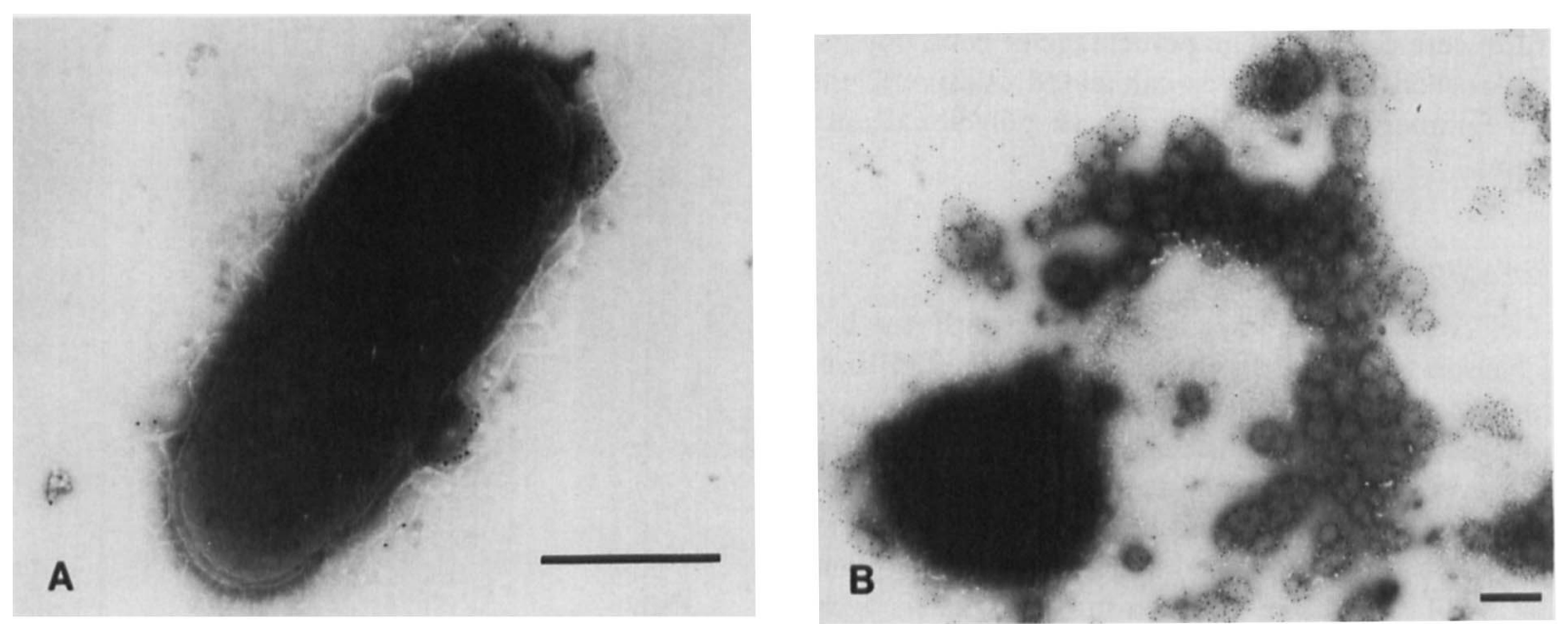

Fig. 2. Negative stained electronmicrographs of (A) the small capsule and (B) the large capsule populations of $B$. fragilis immunogold labelled with MAb QUBf5. Note the labelling of excreted vesicles. Bar, $0.5 \mu \mathrm{m}$.

antigens were released from the large capsule population in association with membrane vesicles (fig. 4C) and from the EDL population as membrane vesicles and cell-free material (fig. 4D).

$M A b$ QUBf8. An $\mathrm{IgG}_{1}$ MAb, QUBf8, was shown by immunoblotting to recognise a high- $\mathrm{M}_{\mathrm{r}}$ polysaccharide which produced a diffuse staining band on the top half of the blot (fig. $1 \mathrm{j}, \mathrm{k}$ and $\mathrm{l}$ ). Faint labelling was detected just behind the gel front in the region of the rough LPS. The QUBf8 epitope was most readily detected in the EDL populations where a fine ladder was seen in the middle region of the blot (fig. 11), As with the other MAbs, the antigen recognised was present in smaller quantities in the small capsule population (fig. 1k). The QUBf8 epitope was shown by thin-section immuno-electronmicroscopy to be expressed on a high proportion of cells from the large capsule and the EDL populations (not illustrated). Negative staining revealed that the polysaccharide was cell associated but could be released from the large capsule population in association with membrane vesicles and from the EDL population as cell-free material (not illustrated).

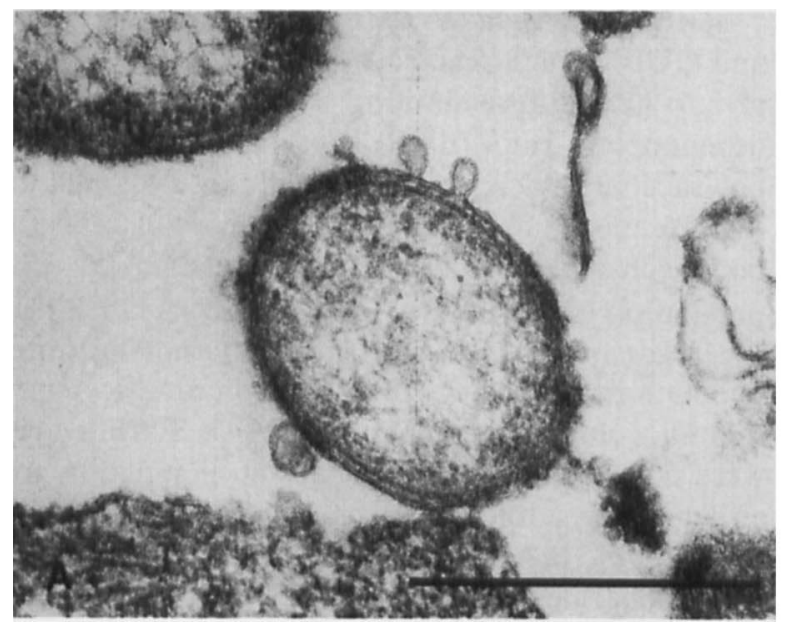

\section{Immunoblotting of outer membrane extracts}

The immunoblotting patterns of Sarkosyl-extracted outer membranes were similar to those obtained by proteinase $\mathrm{K}$ extraction (fig. 1). No additional bands were identified in the outer-membrane preparations, indicating that protein antigens were not detected by any of the MAbs.

\section{Confirmation of MAb specificity by immunofluorescence microscopy and flow cytometry}

The pattern of labelling of the large capsule, small capsule and EDL populations with the MAbs was confirmed by immunófluorescence microscopy and flow cytometry. Strong labelling was associated with the small capsule populations in the case of MAb Bf4 and with the large capsule and the EDL populations in the case of the other MAbs (table I and fig. 5). The proportion of bacteria labelled within the populations was also measured (table I). For microscopy, populations were labelled at the same time with a rabbit

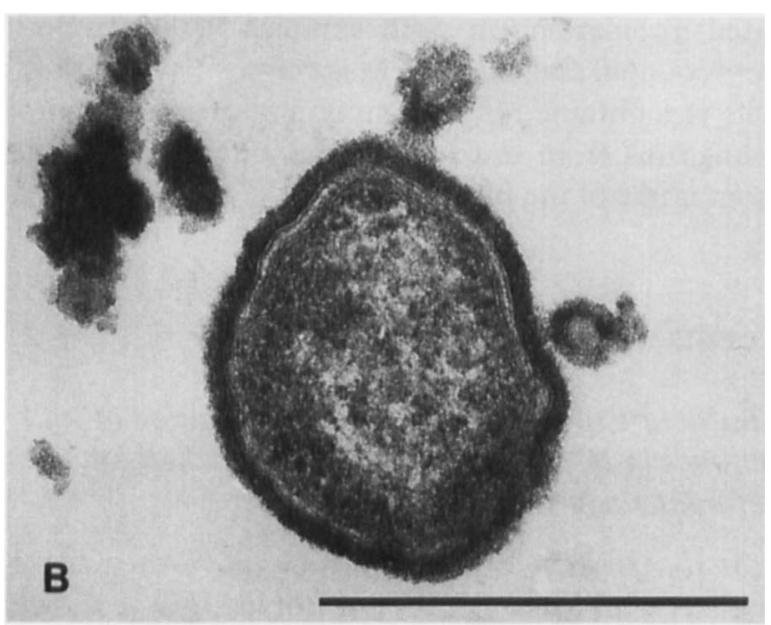

Fig. 3. Thin section electronmicrographs of $\boldsymbol{B}$. fragilis grown in vivo. Note the release of vesicles from the outer membrane (A) and the association of encapsulating material with released vesicles $(\mathbf{B})$. 

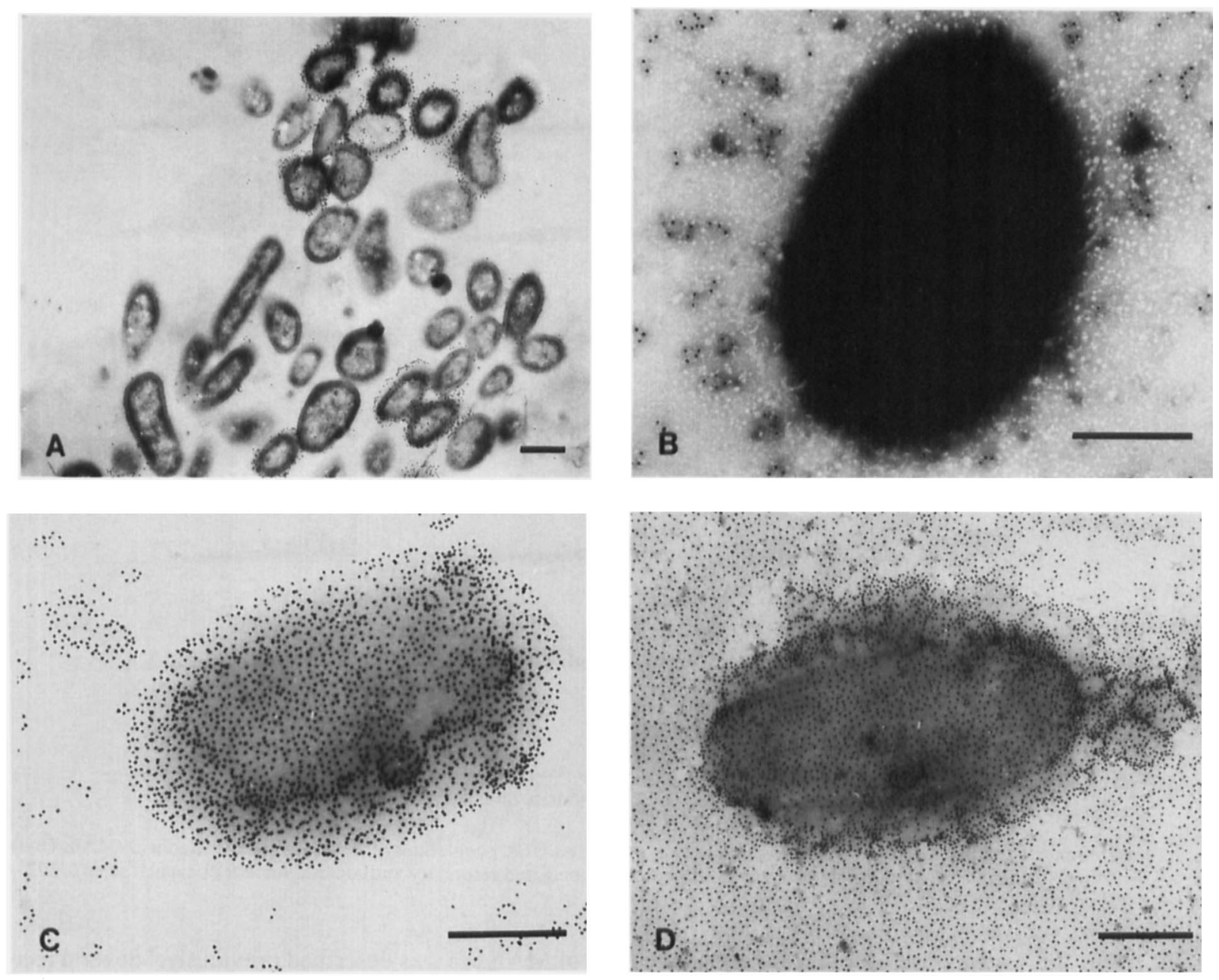

Fig. 4. Electronmicrographs of $B$. fragilis immunogold labelled with MAb QUBf7. (A) Ultra-thin section of the large capsule population; note heterogeneous labelling of bacteria. (B-D) Negatively stained bacteria: (B) small capsule; (C) large capsule and (D) EDL populations; note cell and vesicle association of labelling with large capsule population and cell free material with EDL population.

polyclonal anti-B. fragilis anti-serum (which labelled all the bacteria) and with each of the MAbs. Secondary antibodies of anti-mouse antibody conjugated to fluorescein and anti-rabbit antibody to rhodamine were used to assess the labelling. For flow cytometry, bacteria were identified on the basis of size by forward and $90^{\circ}$ light-scatter signals. Bacterial populations labelled with the nucleic acid-specific fluorochrome propidium iodide and identified in the flow cytometer by a red fluorescent signal were identical to those identified by size (unpublished result). Bacteria labelled with the MAbs were identified by the fluorescent

Table I. Variation in MAb labelling in different populations of $\boldsymbol{B}$. fragilis NCTC 9343

\begin{tabular}{|c|c|c|c|c|}
\hline \multirow{3}{*}{$\begin{array}{l}\text { MAb } \\
\text { Bf4 }\end{array}$} & \multirow{3}{*}{$\begin{array}{c}\text { Method of } \\
\text { analysis }\end{array}$} & \multicolumn{3}{|c|}{ Mean (SEM) percentage of population labelled* } \\
\hline & & Large capsule & \multirow{2}{*}{$\begin{array}{c}\text { Small capsule } \\
96 \quad(5) \\
94 \quad(3)\end{array}$} & \multirow{2}{*}{$\frac{\text { EDL }}{4^{0}(4)}$} \\
\hline & & $\begin{array}{ll}3 & (1)^{*} \\
9 & (5) \dagger\end{array}$ & & \\
\hline QUBf5 & $\begin{array}{l}\text { IFM } \\
\text { FC }\end{array}$ & $\begin{array}{ll}16 & (5) \\
23 & (8)\end{array}$ & $1^{0}$ & $\begin{array}{ll}28 & (5) \\
25 & (9)\end{array}$ \\
\hline QUBf6 & $\begin{array}{l}\text { IFM } \\
\text { FC }\end{array}$ & $\begin{array}{ll}14 & (5) \\
37 & (5)\end{array}$ & $7^{0}(7)$ & $\begin{array}{ll}42 & (12) \\
47 & (14)\end{array}$ \\
\hline QUBf7 & $\begin{array}{l}\text { IFM } \\
\text { FC }\end{array}$ & $\begin{array}{lr}47 & (12) \\
73 & (9)\end{array}$ & $\begin{array}{ll}1 & (1) \\
6 & (6)\end{array}$ & $\begin{array}{l}41 \\
57\end{array}$ \\
\hline QUBf8 & $\begin{array}{l}\text { IFM } \\
\text { FC }\end{array}$ & $\begin{array}{ll}19 & (14) \\
77 & (11)\end{array}$ & $5^{0}$ & $\begin{array}{rr}26 & (2) \\
67 & (11)\end{array}$ \\
\hline
\end{tabular}

IFM, immunofluorescence microscopy; FC, flow cytometry.

* Each IFM value represents the mean of percentages from three experiments.

† Each FC value represents the mean of percentages from three experiments for MAbs QUBf7 and 8 and four experiments for the other MAbs. 


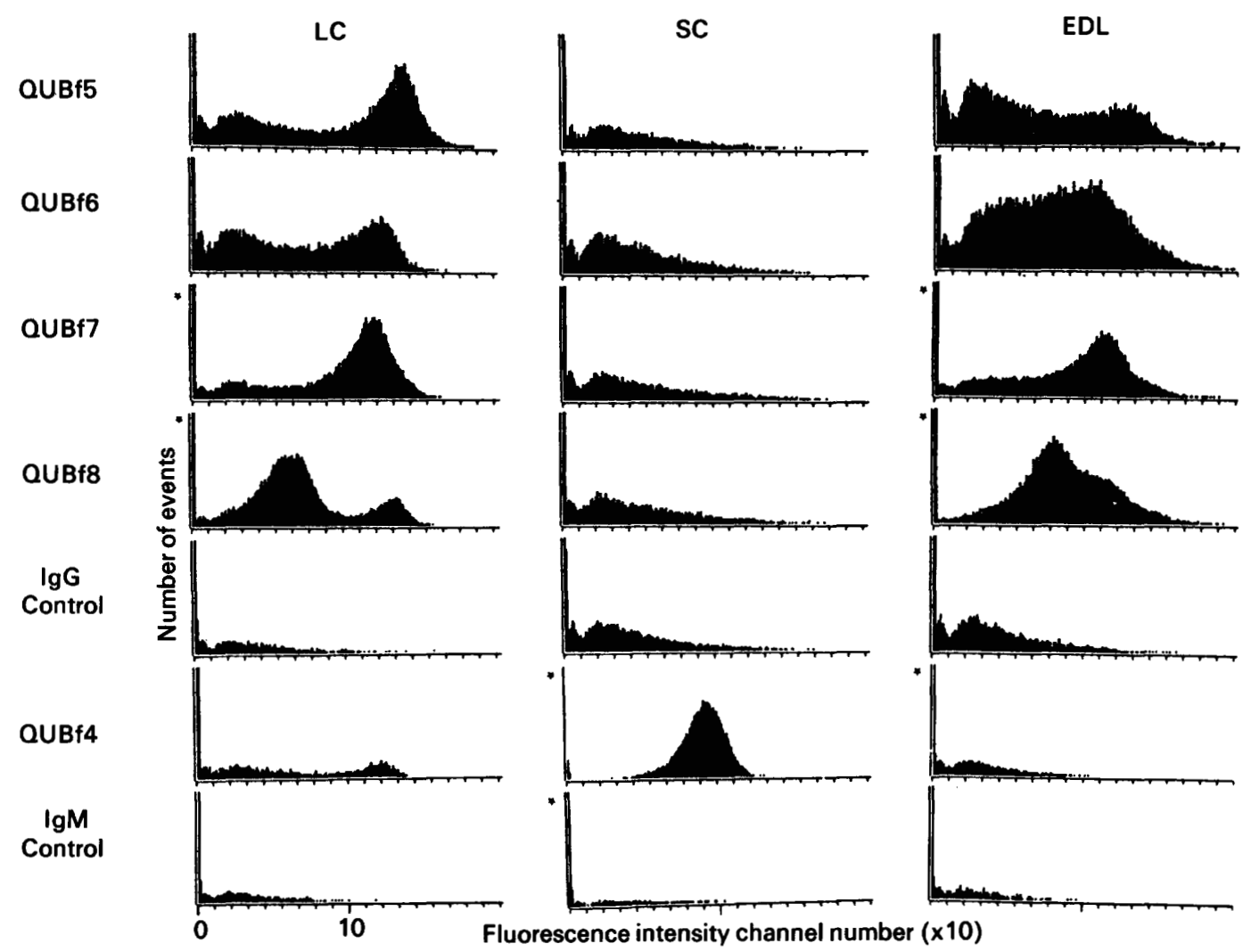

Fig. 5. Flow cytometric profiles. Large capsule (LC), small capsule (SC) and EDL populations of $B$. fragilis were treated with MAbs QUBf58 or Bf 4 or PBS (control) and the appropriate IgG or IgM fluorescein-conjugated secondary antibodies. Number of events: scale 0-1024 (*), 0-512 for other profiles.

signal from an anti-mouse fluorescein-conjugated secondary antibody. Flow cytometry consistently gave higher percentage labelling than fluorescence microscopy for most of the MAbs.

Flow cytometric profiles, which relate to the intensity of fluorescent signal, were obtained consistently in consecutive experiments. Representative profiles are illustrated in fig. 5. MAb QUBf8, labelling the large capsule population, was an exception; although a biphasic profile was consistently obtained, the relative sizes of the two peaks varied. MAbs QUBf5, 6 and 8 all had a biphasic profile when labelling the large capsule population and a much broader profile with the EDL population. A single peak was obtained with MAb QUBf7 for both the LC and EDL populations, and with $\mathrm{MAb} \mathrm{Bf} 4$ for the small capsule population. A small peak at high fluorescent intensity was also apparent in the large capsule population with MAb Bf4. A low level of fluorescent signal was obtained with MAbs 5-8 and the small capsule population.

\section{Cross-reaction of the MAbs with other isolates}

The reactivity of MAbs QUBf5, 6, 7 and 8 with other Bacteroides spp. and with $E$. coli was tested by immunofluorescence microscopy. None of the MAbs cross-reacted with $B$. vulgatus, $B$. thetaiotaomicron, $B$. ovatus, $B$. distasonis, $B$. gingivalis, $E$. coli or $S$. aureus. All reacted with $B$. fragilis strain BE3. The specificity of $\mathrm{MAb} \mathrm{Bf} 4$ was described previously. ${ }^{9}$ Several recent clinical isolates, LS1-11, were screened for reactivity with each of the MAbs. The results are presented in table II.

Populations of B. fragilis NCTC 9343 grown in vivo in the mouse for 7 days showed heterogeneous immunogold labelling with MAbs QUBf7 and 8 (not illustrated).

\section{Discussion}

The exact nature of the polysaccharides produced by $\boldsymbol{B}$. fragilis is not yet clear. LPS of $\boldsymbol{B}$. fragilis was characterised chemically and immunochemically by Kasper et al. ${ }^{19}$ and Weintraub et al. ${ }^{20}$ The extraction

Table II. Reactivity of $B$. fragilis MAbs with a range of recent clinical isolates of $B$. fragilis

\begin{tabular}{lc}
\hline MAb & $\begin{array}{c}\text { Number of isolates* which showed } \\
\text { positive fluorescence with MAb }\end{array}$ \\
\hline Bf4 & 11 \\
QUBf5 & 5 \\
QUBf6 & 4 \\
QUBf7 & 6 \\
QUBf8 & 5 \\
\hline
\end{tabular}

* A total of 11 isolates (LS1-11) was screened with each MAb. 
and separation procedures used in both studies resulted in the selection of only the rough form of $B$. fragilis LPS. Further assays by gel electrophoresis of the crude aqueous phase obtained by phenol-water extraction or the PCP-insoluble fraction repeatedly failed to detect the ladder-like pattern characteristic of O-antigen. ${ }^{22}$ However, Poxton and Brown ${ }^{10}$ extracted LPS from $B$. fragilis by the classical aqueous phenol technique and demonstrated that, in most strains, LPS was present as predominantly smooth type. SDS-PAGE analysis revealed regularly spaced ladder patterns of smooth LPS molecules possessing increasing numbers of $\mathrm{O}-$ antigen repeating units. Linko-Kettunun et al. produced MAbs to the LPS of $B$. fragilis. ${ }^{22}$ Each MAb recognised a common galactose-containing determinant present in the outer core of the rough LPS. ${ }^{23}$ The absence of the long chains of repeating polysaccharide units led the authors to conclude that $\boldsymbol{B}$. fragilis LPS resembled the rough type LPS of gram-negative bacteria. ${ }^{24}$

The MAbs described in the present study all reacted with saccharide epitopes. By immunoblotting, MAb QUBf5 reacted with $B$. fragilis antigens to produce a ladder in the middle of the blot similar to the ladder which Poxton and Brown suggested was the $\mathrm{O}$ antigen. ${ }^{10}$ MAbs QUBf6 and QUBf7 were specific for different high- $M_{r}$ polysaccharides. MAb QUBf8 labelled high $\mathbf{M}_{r}$ polysaccharide and also some low $\mathbf{M}_{r}$ material which stained in a similar position to the core region of the rough LPS from other bacteria. This indicates that the Bf8 epitope may be present on a core or anchoring region of the polysaccharide.

Therefore, by using whole bacteria as antigens for both immunisation and MAb screening, we obtained a broader range of MAbs, including one which may be to the $\mathrm{O}$-antigen.

Immuno-electronmicroscopy showed that these MAbs labelled epitopes primarily associated with the large capsule and EDL, but not the small capsule. In the case of the large capsule population, MAbs QUBf5-8 recognised epitopes present on both the bacterial surface and extracellular vesicles. The membrane vesicles either remained within the fibrous network of the large capsule or were sloughed off. Since extracellular vesicles may have associated capsular or EDL material, it remains unclear whether the saccharide epitopes are associated with the membrane bilayer or the encapsulating structures. Deslauriers et al. observed the release of similar extracellular vesicles from intact Porphyromonas (Bacteroides) gingivalis cells. ${ }^{25}$ The extracellular vesicles described consisted of a membrane bilayer and were thought to contain some periplasmic material. The release of extracellular OM vesicles has previously been described in $E$. coli growing under lysine limitation ${ }^{26}$ and also under normal growth conditions. ${ }^{27}$ Such a release of membrane vesicles or slime may be important in virulence. The antigenic sites located on extracellular structures could result in the deposition of opsonin, either $\mathrm{C} 3$ or specific antibody, at a distance from the bacterial cell, thus reducing the effectiveness of the host immune response.

The reaction of each of the anti-polysaccharide MAbs with a proportion of recent clinical isolates and bacteria grown in vivo suggests that these polysaccharides may be relevant to the virulence of $B$. fragilis.

In contrast with the large capsule population, in the EDL population the saccharide epitopes were not firmly surface-associated. Polysaccharides are abundantly released from these cells as free material, probably in the form of slime (fig. 4d) similar to that observed in other bacteria and described as excreted viscous substances that are not anchored in the bacterial outer membrane. ${ }^{28}$

Interestingly, the ladder pattern observed by immunoblotting was associated only with the EDL population. These ladders are considered to represent polysaccharide molecules of varying chain lengths, each step up the ladder corresponding to the addition of one repeating subunit. Perhaps the polysaccharides from cells in the EDL population are of varying chain lengths, or they are more susceptible to breakage of the chain. Where the polysaccharides remain solely cell- or vesicle-associated, in the case of the large capsule population, the chains may remain large and intact.

There was a low level of labelling of the small capsule population detectable by flow cytometry, immunoblotting and immunogold electronmicroscopy with negative stain. There are a number of possible explanations of this. Firstly, as the MAb only labelled extracted and secreted material and not whole cells, it is possible that the antigenic sites are masked by other structures. However, electronmicroscopy and immunogold labelling of thin sections gave a negative result and, therefore, did not support this hypothesis. Secondly, a low proportion of cells from the large capsule or EDL population may have been present in the sample. Thirdly, the polysaccharides may be expressed at a low level because of incomplete repression of the genes involved in controlling polysaccharide synthesis. A few labelled outer membrane vesicles were observed in the small capsule population (fig. 2a).

Flow cytometry provided further confirmation of the labelling pattern of the four MAbs QUBf5-8 and of $\mathrm{MAb} \mathrm{Bf} 4$ which reacted with the small capsule. It also allowed a more rapid and accurate measurement of the proportion of bacteria labelled within a given population.

The generally higher percentage labelling obtained by flow cytometry, when compared with fluorescence microscopy, may be due to the greater sensitivity of the flow cytometer which detects fluorescence signals not readily visible by eye. Alternatively, it may be due to the harsher fixation procedure used for microscopy. This may cause the loss of some antigenic sites.

The significance of the fluorescent intensity profiles obtained by flow cytometry is at yet unclear, although they were consistently reproducible. The twin peaks 
obtained with MAbs 5, 6 and 8 and the large capsule population may represent different populations within the large capsule population. Whether this occurs as a natural pheonomenon or as a result of the treatment of bacteria during the labelling procedure is under investigation. These MAbs gave a broad profile when labelling the EDL population. The electronmicroscopy results show that polysaccharides labelled by these MAbs are released as cell-free material from the EDL population. Therefore, the broad profile may represent a continuum from cells from which most of the polysaccharide has been released as free material, to those in which most of it remains associated with the bacterial cell. Ørskov and Ørskov ${ }^{30}$ noted that even the mildest extraction procedures, such as cautious suspension of $E$. coli in saline, gives a suspension containing capsular material and LPS. More discrete peaks (e.g., small capsule population with MAb Bf4) may relate to the closer association of the polysaccharide with the cell surface.

We have shown previously that the EDL population agglutinates erythrocytes from a number of different animal species. ${ }^{29}$ The present study shows that a proportion of the bacteria within these populations share common epitopes. The polysaccharides recognised by the MAbs may not be involved in haemagglutination. Alternatively, the polysaccharides may have different properties in the large capsule and EDL populations. This might relate in some way to the variation in polysaccharide chain length detected by immunoblotting only in the EDL population.

\section{References}

1. Finegold SM. General aspects of anaerobic infection. In: Finegold SM, George WL (eds) Anaerobic infections in humans. San Diego, Academic Press. 1989: 137-153.

2. Hofstad $T$. Virulence determinants in nonsporeforming anaerobic bacteria. Scand J Infect Dis 1989; Suppl 62: 15-24.

3. Kasper DL. The polysaccharide capsule of Bacteroides fragilis subspecies fragilis: immunochemical and morphologic definition. J Infect Dis 1976; 133: 79-87.

4. Babb JI, Cummins CS. Encapsulation of Bacteroides species. Infect Immun 1978; 19: 1088-1091.

5. Lambe DW, Mayberry-Carson KJ, Ferguson KP, Costerton JW. Morphological stabilization of the glycocalyces of 23 strains of five Bacteroides species using specific antisera. Can J Microbiol 1984; 30: 809-819.

6. Weintraub A, Larsson BE, Lindberg AA. Chemical and immunochemical analyses of Bacteroides fragilis lipopolysaccharides. Infect Immun 1985; 49: 197-201.

7. Patrick S, Reid JH, Coffey A. Capsulation of in vitro and in vivo grown Bacteroides species. J Gen Microbiol 1986; 132: 1099-1109.

8. Reid JH, Patrick S, Dermott E, Trudgett A, Tabaqchali S. Investigation of antigenic expression of Bacteroides fragilis by immunogold labelling and immunoblotting with monoclonal antibody. FEMS Microbiol Lett 1985; 30: 289-293.

9. Reid JH, Patrick S, Tabaqchali S. Immunochemical characterization of a polysaccharide antigen of Bacteroides fragilis with an IgM monoclonal antibody. J Gen Microbiol 1987; 133: 171-179.

10. Poxton IR, Brown R. Immunochemistry of the surface carbohydrate antigens of Bacteroides fragilis and definition of the common antigen. J Gen Microbiol 1986; 132: 24752481.

11. Van Tassell RL, Wilkins TD. Isolation of auxotrophs of Bacteroides fragilis. Can J Microbiol 1978; 24: 1619-1621.
The factors governing the differential expression of the same saccharide epitopes in the large capsule, the small capsule and the EDL populations of $B$. fragilis are unclear. Ørskov and Ørskov described form variation in $E$. coli $\mathrm{K} 1$ strains. $^{28}$ In the same $\mathrm{K} 1$ antigen cultures two types of colony were found with different reactivity towards a $\mathrm{K} 1$ antiserum. It was suggested that antigenic phase variation occurred in E. coli $\mathrm{O} 26 / \mathrm{B}^{3}{ }^{30}$ Two distinct phenotypic variants, which showed differences in reactivity with a corespecific MAb, were identified by flow cytometry. Similar antigenic variation may occur in $B$. fragilis and may be important in the virulence of this bacterium.

Structural differences, observed by electronmicroscopy, within individual strains of $\boldsymbol{B}$. fragilis are reflected by differences in antigenicity. There is also, antigenic variation within structurally homogeneous populations of $B$. fragilis. Therefore, it seems likely that antigenic variation may occur in $B$. fragilis and the epitopes expressed by individual cells may reflect the selective pressures imposed on the population at a given time. The stability of epitope expression in relation to the virulence of $B$. fragilis is the subject of current investigations.

We thank Mr B. O'Loughlin for technical assistance, and Dr N. Damani and Mr J. McCallum, Bacteriology Laboratory, Craigavon Area Hospital for their co-operation. D.A.L. and the work were funded by M.R.C. Grant No. G8618252SB.

12. Patrick S, Lutton DA. Outer membrane proteins of Bacteroides fragilis grown in vivo. FEMS Microbiol Lett 1990; 71 : 1-4.

13. Brown R, Hornett KE, Poxton IR. Immunochemistry of the cell surfaces of Bacteroides bivius and Bacteroides disiens. $J$ Med Microbiol 1989; 28: 267-273.

14. Galfrè G, Milstein C. Preparation of monoclonal antibodies: strategies and procedures. Methods Enzymol 1981; 73: $1-46$.

15. Laemmli UK. Cleavage of structural proteins during the assembly of the head of bacteriophage T4. Nature 1970; 227: $680-685$.

16. Patrick S, Reid JH, Larkin MJ. The growth and survival of capsulate and non-capsulate Bacteroides fragilis in vivo and in vitro. J Med Microbiol 1984; 17: 237-246.

17. Johnson GD, Holborow EJ, Dorling J. Immunofluorescence and immunoenzyme techniques. In: Weir DM (ed) Handbook of experimental immunology, 3rd edn. Oxford, Blackwell Scientific Publications. 1978: Chapter 15.

18. Nelson D, Neill W, Poxton IR. A comparison of immunoblotting, flow cytometry and ELISA to monitor the binding of anti-lipopolysaccharide monoclonal antibodies. J Immunol Methods 1990; 133: 227-233.

19. Kasper DL, Weintraub A, Lindberg AA, Lönngren J. Capsular polysaccharides and lipopolysaccharides from two Bacteroides fragilis reference strains : chemical and immunochemical characterization. J Bacteriol 1983; 153 : 991-997.

20. Weintraub A, Zähringer U, Lindberg AA. Structural studies of the polysaccharide part of the cell wall lipopolysaccharide from Bacteroides fragilis NCTC 9343. Eur J Biochem 1985; 151 : $657-661$.

21. Lindberg AA, Weintraub A, Zähringer U, Rietschel ET. Structure-activity relationships in lipopolysaccharides of Bacteroides fragilis. Rev Infect Dis 1990; 12 Suppl 2: S133S141.

22. Linko-Kettunen L, Arstila P, Jalkanen $M$ et al. Monoclonal 
antibodies to Bacteroides fragilis lipopolysaccharide. J Clin Microbiol 1984; 20: 519-524.

23. Linko L, Weintraub A, Arstila P, Pelliniemi LJ, Viljanen MK Characterization of the common immunodominant antigenic determinant in the lipopolysaccharide of Bacteroides fragilis by a monoclonal antibody. Scand J Immunol 1987; 25: 469-475.

24. Viljanen MK, Linko L, Arstila P, Lehtonen O-P, Weintraub A Monoclonal antibodies to the lipopolysaccharide and capsular polysaccharide of Bacteroides fragilis. In: Macario AJL, Macario EC (eds) Monoclonal antibodies against bacteria, vol. 3. Orlando, Academic Press. 1986: 119-142.

25. Deslauriers M, ni Eidhid D, Lamonde L, Mouton C. SDSPAGE analysis of protein and lipopolysaccharide of extracellular vesicles and Sarkosyl-insoluble membranes from Bacteroides gingivalis. Oral Microbiol Immunol 1990; 5: $1-7$.

26. Knox KW, Vesk M, Work E. Relation between excreted lipopolysaccharide complexes and surface structures of a lysine-limited culture of Escherichia coli. $J$ Bacteriol 1966; 92: 1206-1217.

27. Hoekstra D, Van der Laan JM, De Leij L, Witholt B. Release of outer membrane fragments from normally growing Escherichia coli. Biochim Biophys Acta 1976; 455: 889-899.

28. Ørskov F, Ørskov I. The serology of capsular antigens. In: Jann $\mathrm{K}$, Jann B (eds) Bacterial capsules (Current topics in microbiology and immunology, vol 150). Berlin, SpringerVerlag. 1989: 43-63.

29. Patrick S, Coffey A, Emmerson AM, Larkin M. The relationship between cell surface structure expression and haemagglutination in Bacteroides fragilis. FEMS Microbiol Letts 1988; 50: $67-71$.

30. Evans ME, Pollack M, Hardegen NJ, Koles NL, Guelde G, Chia JKS. Fluorescence-activate cell sorter analysis of binding by lipopolysaccharide-specific monoclonal antibodies to gram-negative bacteria. J Infect Dis 1990; 162: 148-155. 